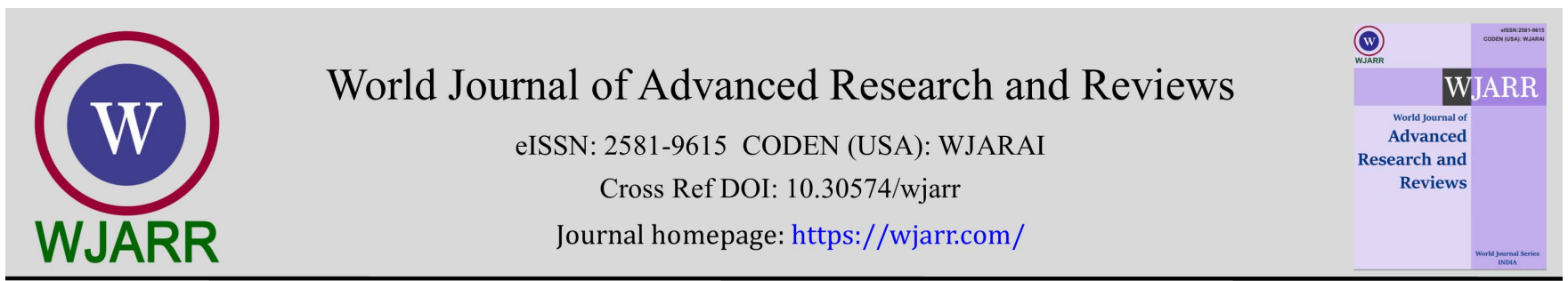

(RESEARCH ARTicle)

\title{
Impact of family planning logistic management models on uptake of contraceptives in selected states in Nigeria: A comparative retrospective analysis
}

Abayomi Joseph Afe 1, ${ }^{*}$, Emmanuel Emmesowum 1, Omolaso Omosehin 2, Yakubu Aliyu 1, Olanrewaju Alabi 1, Idowu Araoyinbo ${ }^{1}$, Theresa Adah ${ }^{1}$, Ulla Mueller ${ }^{3}$, Erika Goldson ${ }^{3}$, Joachim Chijide ${ }^{3}$ and Jacque Karungi ${ }^{1}$

${ }^{1}$ UNFPA, Cross River Sub-Office, Nigeria.
${ }^{2}$ UNFPA, Lagos state Sub-Office, Nigeria.
${ }^{3}$ UNFPA, Country Office, Nigeria.

World Journal of Advanced Research and Reviews, 2022, 13(02), 210-218

Publication history: Received on 24 December 2021; revised on 07 February 2022; accepted on 09 February 2022

Article DOI: https://doi.org/10.30574/wjarr.2022.13.2.0101

\begin{abstract}
Background: Use of contraceptives improves individual and national health outcomes and indices as it prevents maternal mortality and morbidity, child mortality, incidence of sexually transmitted infections and retains adolescents and young girls in school with improvement in the economic earning power. Contraceptive Logistics is the supply of contraceptives in the right quantity and quality at the right place at the right time for the right cost to the right people. The Contraceptive Logistics Management System in Nigeria stipulates that to ensure uninterrupted product availability and minimal stock out, Family Planning Service Delivery Points (SDPs) are to be re-supplied on a bi-monthly basis to bring their stock level to a maximum of 4 months of stock at any given time.
\end{abstract}

Method: A retrospective analysis of the impacts of the three logistic models operational in six southern states in Nigeria under the auspice of UNFPA funded family planning logistics supply chain. Three outcomes of interest used to assess the impacts were stock out rates, gaps in supply and proportion of new users of contraceptives. The three models of family planning logistics reviewed were direct government last mile distribution with external funding, direct government last mile distribution without external funding and a third party private logistic company last mile distribution

Result: The stock out rates for the direct government logistics with external funding was 6-20\%, the direct government logistics last mile distribution (LMD) without external funding had a stock out rate of 20-58\% and the private logistic company last mile distribution had a stock out rate of 10-30\%. In terms of the gap in supply, the supply gap with the direct government LMD with external funding model was 48\%, while the direct government LMD with no external funding model had a supply gap of $73 \%$ and the private company LMD logistics model had a low supply gap of $28 \%$. The proportion of FP users who were new users was 19\% in the direct government LMD with external funding, $8 \%$ in direct government LMD without external funding, and 16\% in private logistic company LMD.

Discussion: Direct government last mile distribution (LMD) with external funding reached the highest number of new FP users followed by private logistic company LMD and therefore contributed the greatest to the reduction of unmet need in family planning and increasing the contraceptive prevalence rates. The highest stock out rate of contraceptives was associated with direct government LMD without external funding and the least stock out rate was associated with same direct government LMD but with external funding. The greatest gap in supply of contraceptives was seen with direct government LMD without external funding followed by direct government LMD with external funding. Private company LMD had the least supply gap in contraceptives.

\footnotetext{
${ }^{*}$ Corresponding author: Abayomi Joseph Afe

UNFPA, Cross River Sub-Office, Nigeria. 
Keywords: Family planning; Contraceptive; Logistics; Service Delivery points; Last mile distribution

\section{Introduction}

Family planning can be defined as an intervention comprising services, policies, information, attitude, practices and commodities including contraceptive which empower women, men, couple and adolescents with the ability to avoid unintended pregnancy and choose whether and when to give birth [1].

Globally there has been increases in contraceptive use in the last several decades yet an estimated 214million women of reproductive age have an unmet need for contraception in developing regions [2]. Among the multiple reasons for this include the poor geographical or financial access, health concerns or side effects, and low decision-making power [3-6]. Meeting the unmet need for contraception in developing regions would avert an estimated 67million unintended pregnancies, 36million induced abortions, and 76,000 maternal deaths each year [2]

Access to contraceptives is recognized to play a key role in the achievement of many national and international goals such as the set targets for modern contraceptive prevalence rate(mCPR) at national and global levels, the sustainable development goals 3.7 (universal access to sexual and reproductive healthcare services) and FP2030 targets and objectives [1]

Ensuring access to contraception is fundamental to human rights as it advances the rights of people to determine the number and spacing of their children.

Use of contraceptives improves individual and national health outcomes and indices as it prevents maternal mortality and morbidity, child mortality, reduce incidence of sexually transmitted infections and retains adolescents and young girls in school with improvement in the economic earning power.

Nigeria is the most populous nation in Africa and has a rapidly growing population. The estimated population is over 200 million as at midyear 2020, out of which about 46 million are women of reproductive age (WRA). With a total fertility rate (TFR) of 5.3 and a low contraceptive prevalence rate of $14.3 \%$, Nigeria's population is likely to hit 379 million by 2050, becoming the fourth most populous country on earth (7]. Also at that rate it would take only about 30 years for population of Nigeria to double itself. The high fertility and mortality patterns have resulted in a young population structure, with more than $40 \%$ of the current population being children under the age of 15 years.

The percentage of Nigerian women who want to space their births or do not want to get pregnant but not using contraception is $23.6 \%$ (unmet need) while the proportion of demand satisfied by modern methods is just $34 \%$ (7).

There is high knowledge of contraceptive use in Nigeria (92.1\% in women and $93.8 \%$ in men) in the face of the low contraceptive rate. This shows that access to contraceptive device may be one of the major reasons for the high unmet need.

Challenges in access to contraceptives use are due to poor or lack of supply of contraceptives and or difficult terrain that make movement to facility or locations where these are available very difficult. Societal stigma and negative sociocultural beliefs have also been identified as barriers to access especially among the youths and adolescent.

Logistic challenges leading to poor or lack of supply of contraceptives seem to be the easiest to address of all the access issues in the contraceptive use. This is achievable with adequate funding and technical support

Therefore, our work focusses on reviewing the impact of the various logistic methods adopted in improving access to contraceptive use in the six states of the south-south, southeast and north-central geopolitical zones in Nigeria.

Contraceptive Logistics is the supply of contraceptives in the right quantity and quality at the right place at the right time for the right cost to the right people.

The contraceptive logistics management system in Nigeria stipulates that to ensure uninterrupted product availability and minimal stock out, family planning service delivery points (SDPs) are to be re-supplied on a bi-monthly basis to bring their stock level to a maximum of 4 months of stock at any given time. This requires last mile distribution (LMD) to be conducted six times in a year. 
The current distribution of family planning commodities in Nigeria can be divided into two stages:

- $\quad$ Long-haul distribution (LHD) from Central Contraceptive Warehouse to State stores

- Last Mile Distribution (LMD) from state stores to service delivery points (SDPs) or via LGA stores.

The Federal Ministry of Health is responsible for long-haul distribution, while the states and local governments are responsible for the LMD. The long-haul distribution while largely effective is plagued with bottlenecks related to delayed state reports, limited funding and commodity unavailability and delay in implementing scheduled distributions [8].

Similarly, there are challenges with the last mile distribution to the SDPs such as inadequate resources/funds, particularly funding for commodity transportation. This limitation in funds has stalled distribution and increased stock out rates. . Presently, LMD of contraceptives in Nigeria are saddled with sustainability challenges as they are majorly donor/partner driven.

Ensuring the regular distribution of contraceptive commodities to SDPs in the long-term requires each state to establish and fund its own process for the LMD of contraceptive commodities. Part of these efforts include system wide strengthening interventions, such as the formation of a State Logistics Management Coordination Unit (LMCU) and the planned integration of parallel health supply chains in the country through the National Product Supply Chain Management Programme (NPSCMP).

The LMD mode of operation entails local government authority (LGA) logisticians visiting each public health facility to obtain their consumption and request reports monthly. These reports are reviewed bimonthly at the state level and sent to the National level for us in the development of distribution plans. On reaching the state from the National warehouse the contraceptive commodities are kept in the state warehouse in preparation for last mile distribution (LMD) to the public health facilities.

Bringing the Contraceptives to the point of service delivery and making sure they reach the last mile are critical links in the logistics systems that support product availability.

\subsection{Nigeria national family planning procurement and logistics system.}

United Nations Population Fund (UNFPA) support the government of Nigeria to ensure sustained universal access to and use of Family Planning (FP) commodities by men, women and young people of reproductive age. This support is provided through a right-based approach which aim to fulfill the rights of all individuals to choose whether, when, and how many children to have and to act on those choices through high quality FP information, services and commodities. UNFPA is the leading procurer of contraceptives for the public sector in Nigeria, [9]. This is done through a pooled procurement mechanism used by UNFPA Supply Programme to procure commodities for 46 countries (including Nigeria) at the most competitive negotiated prices with manufacturers, while ensuring the highest quality and standards of contraceptives.

The family planning procurement in Nigeria uses the basket fund approach which is a funding mechanism whereby financing entities such as governments and donors place their funds into a single account (Basket Fund) and withdraw funds to meet specified objectives. This funding mechanism increases country 'ownership', strengthen country leadership, support market shaping to reduce market inefficiencies and improve contraceptive commodity security in Nigeria.

UNFPA Nigeria provides support to last mile distribution, capacity building of service providers on logistics management and coordination by procurement supply chain management (PSM) sub committees on tracking FP commodities distribution to states and service delivery points (SDPs). This support started after 2011 when the user fees for FP commodities was removed. Before then the user fees or cost recovery model for contraceptives in public health sector were used to support distribution of contraceptives but in order to improve access to FP commodities the practice was revoked.

Currently UNFPA Nigeria is funding the implementation of LMD to 16 states. The implementation is through an NGO in 13 states using IMPACT team model and in 3 states through a state-owned third-party logistics service provider (3PL). While other states which are not currently covered by these interventions are using alternative methods of distribution, some of which do not deliver the FP commodities to the SDPs but to the local government area (LGA) stores, avoiding the last mile. The Last mile distribution in some states are at ad hoc basis. 
To ensure sustainability, UNFPA advocated for the creation of a budget line item for FP programmes both at the national and state government levels. UNFPA also supported the development of the first National Guidelines for State-Funded Procurement of Family Planning Commodities which serve to define the criteria for qualification and the procurement processes at the state level and document the mechanism to ensure quality in the procurement of quality FP commodities. UNFPA also supports system strengthening interventions, such as the formation of State Logistics Management Coordination Units (LMCU) across the federation units.

Objectives: This study intends to achieve the following objectives

- To discuss the 3 contraceptive logistic management models in use in the zone.

- To compare the primary outcomes of the different models; stock out rates and gaps in supply.

- To compare the secondary outcome of the different models; proportion of new contraceptive users.

\section{Methods}

This is a retrospective review of logistic and service delivery data collected through the three models of family planning logistic management implemented in some states in Nigeria. The states are Abia, Ebonyi and Imo in southeast, Benue in northcentral, Cross River and Akwa Ibom states in south-south regions in Nigeria. The three logistic management models for contraceptives were implemented in these states between May 2019 and May 2020 are listed below.

- Direct Government LMD with external funding: Where LGA FP supervisors collate, report and distribute contraceptives from the state ware house to the health facilities. The funding for this activity was provided by UNFPA through a $3^{\text {rd }}$ party logistic company, which was a non-government organization (NGO). The same $3^{\text {rd }}$ party provided the technical support and monitoring on the intervention. This happened in Abia, Imo, Benue, Cross River states,

- Direct Government LMD with no external funding: Here the LGA FP supervisors collate, report and distribute contraceptives from the state ware house to the health facilities leveraging on the existing government structure with no funding from any external organization. This was the scenario in Akwa Ibom state.

- Direct LMD by a Private Logistic Private Company: Ebonyi State where a Third-Party Logistics (3PL) Company undertakes the whole LMD responsibility. The 3PL was a private company funded by a donor through a development partner. The private company did the physical distribution of the contraceptive commodities to the health facilities in the state. It also conducts the post LMD activity monitoring and reports to the state government and the funder.

\section{Results}

\subsection{Stock out Rate of Family Planning Commodities by Logistic models}

\subsubsection{Direct Government LMD with external funding logistic model}

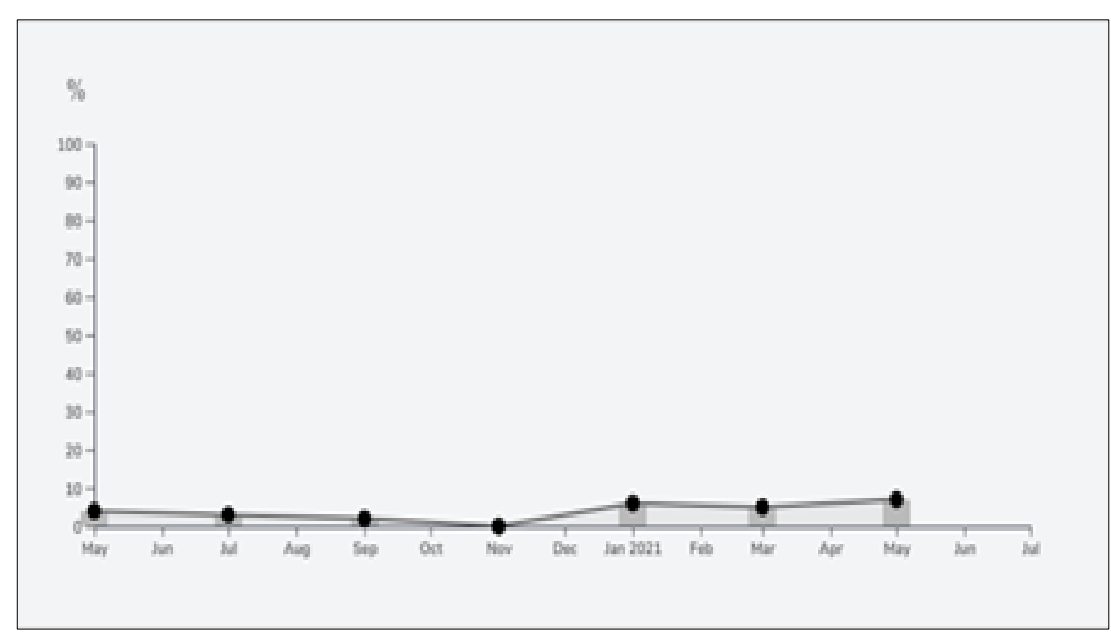

Figure 1 Trend in FP stockout rates May 2019 - May 2020 Abia state 
World Journal of Advanced Research and Reviews, 2022, 13(02), 210-218

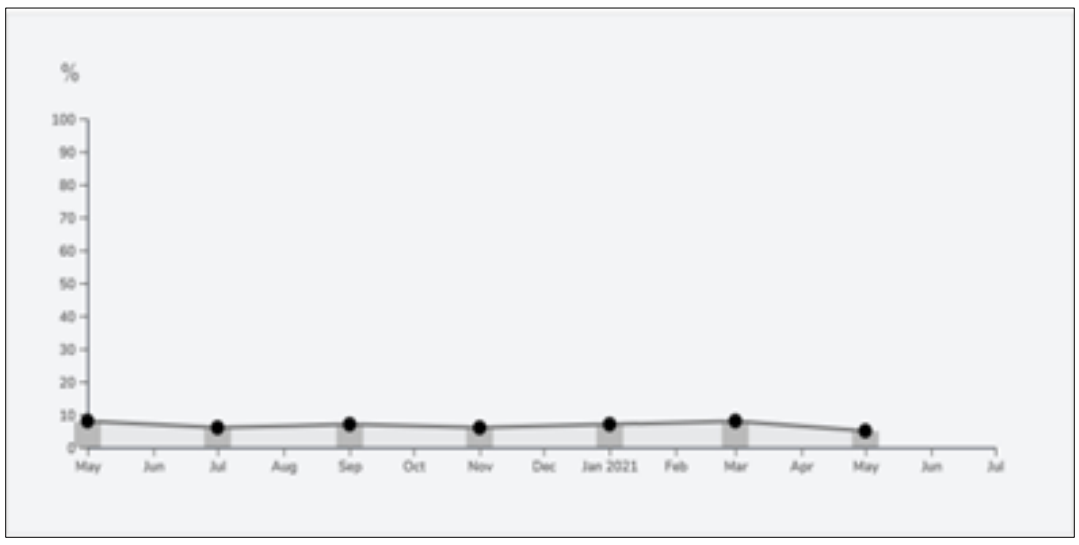

Figure 2 Trend in FP stockout rates May 2019 -May 2020 Imo state

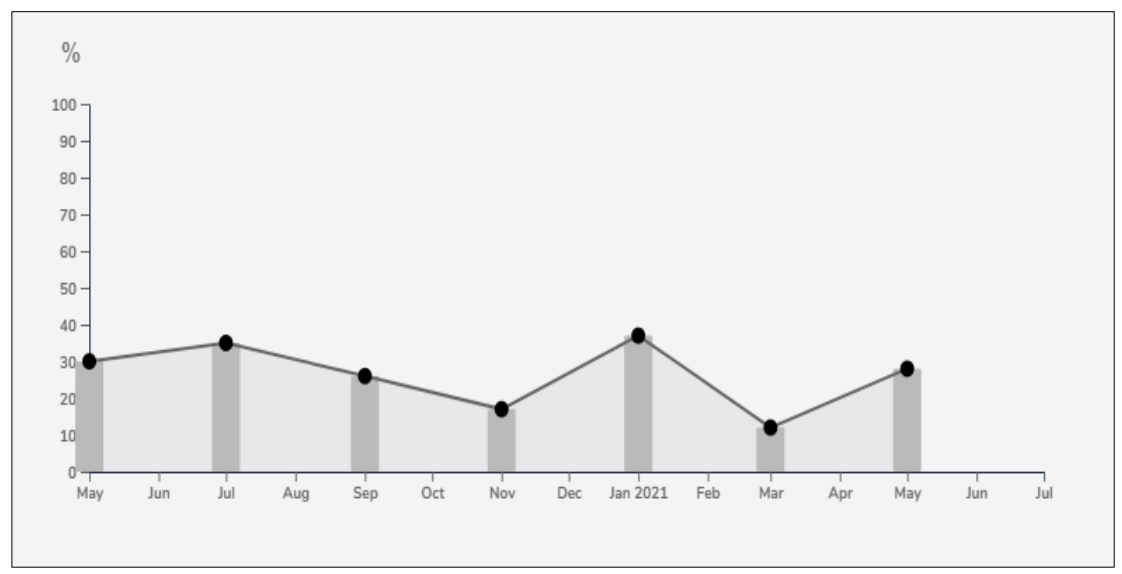

Figure 3 Trend in FP stockout rates May 2019 -May2020 Cross River State

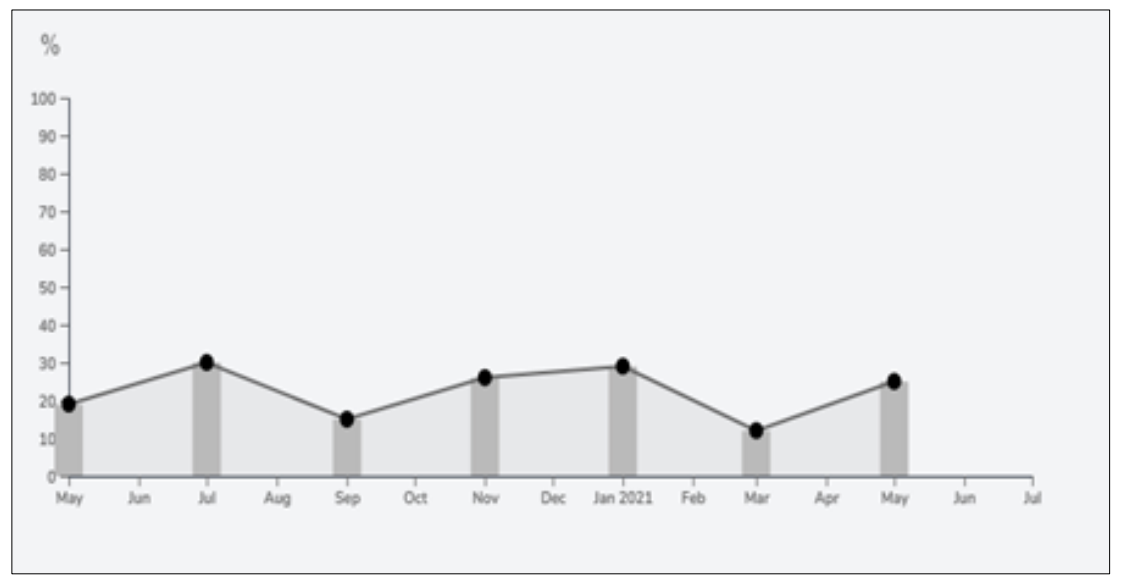

Figure 4 Trend in FP stockout rates May 2019 -May 2020 Benue State 
3.1.2. Direct Government LMD with no external funding logistic model

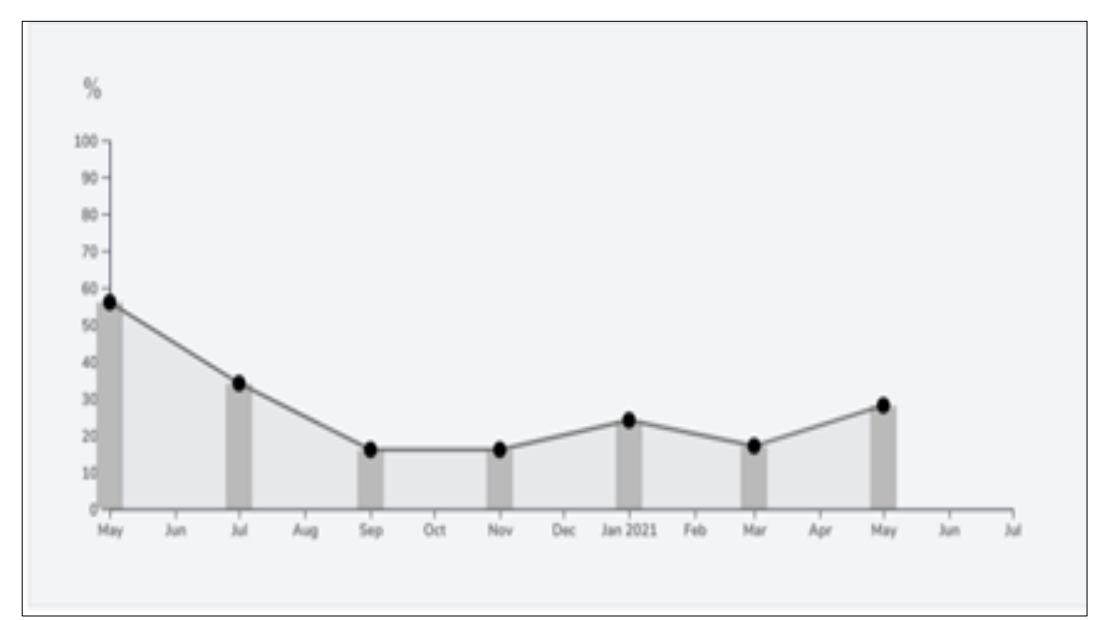

Figure 5 Trend in FP stockout rates May 2019 - May 2020 in Akwa Ibom

3.1.3. Direct LMD by a Private Logistic Company Logistic model

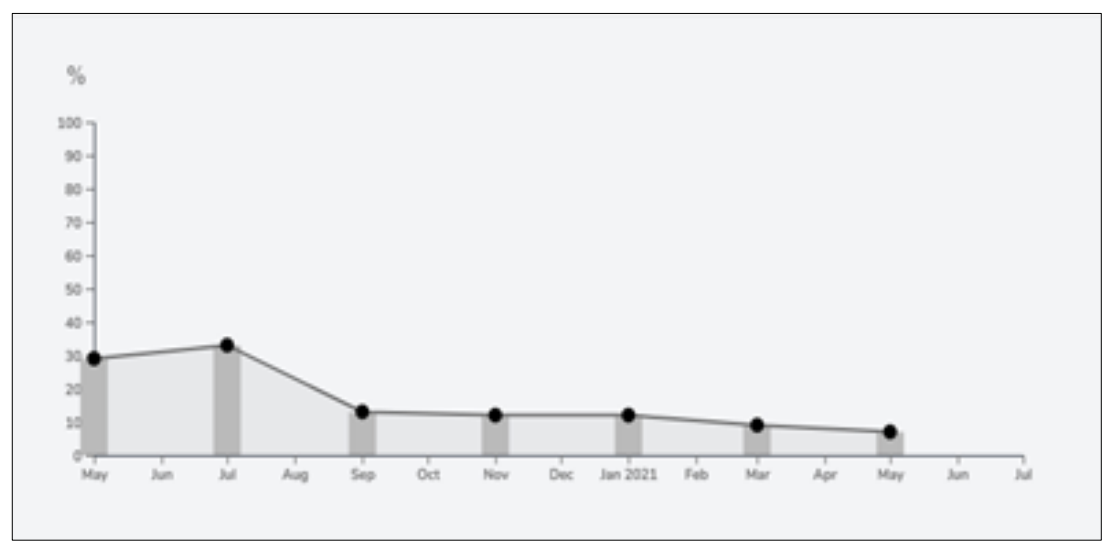

Figure 6 Trend in FP stockout rates May 2019 - May 2020 in Ebonyi state

\subsection{Supply Gap in Family Planning Commodity}

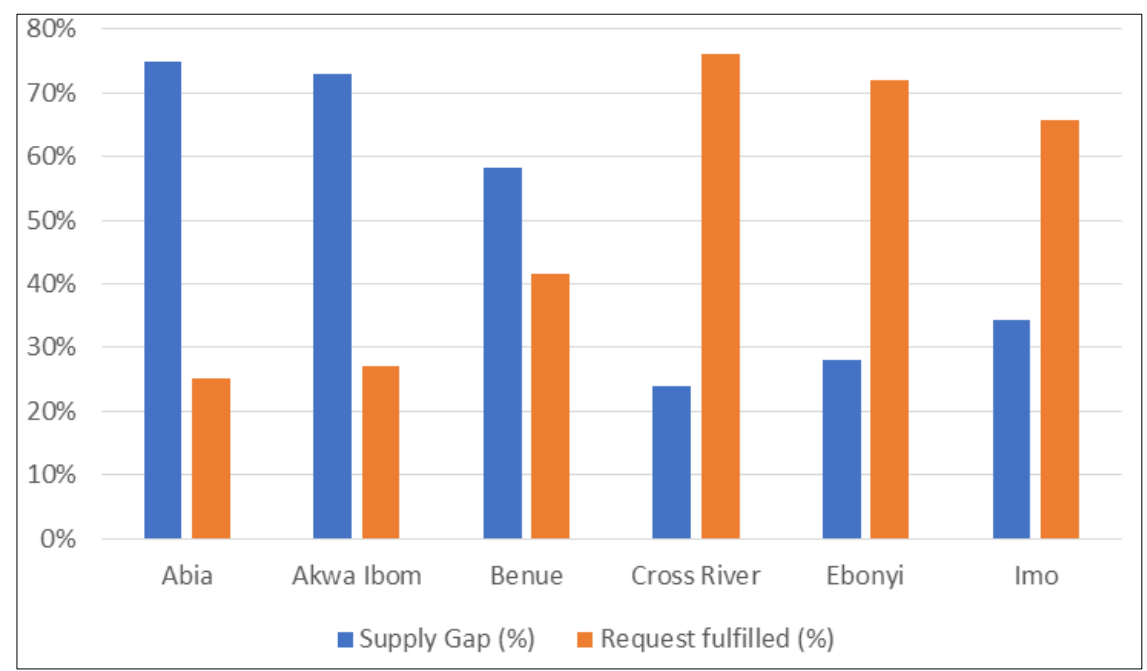

Figure 7 Gaps in supply of FP commodity by states 


\subsection{New Contraceptive Users}

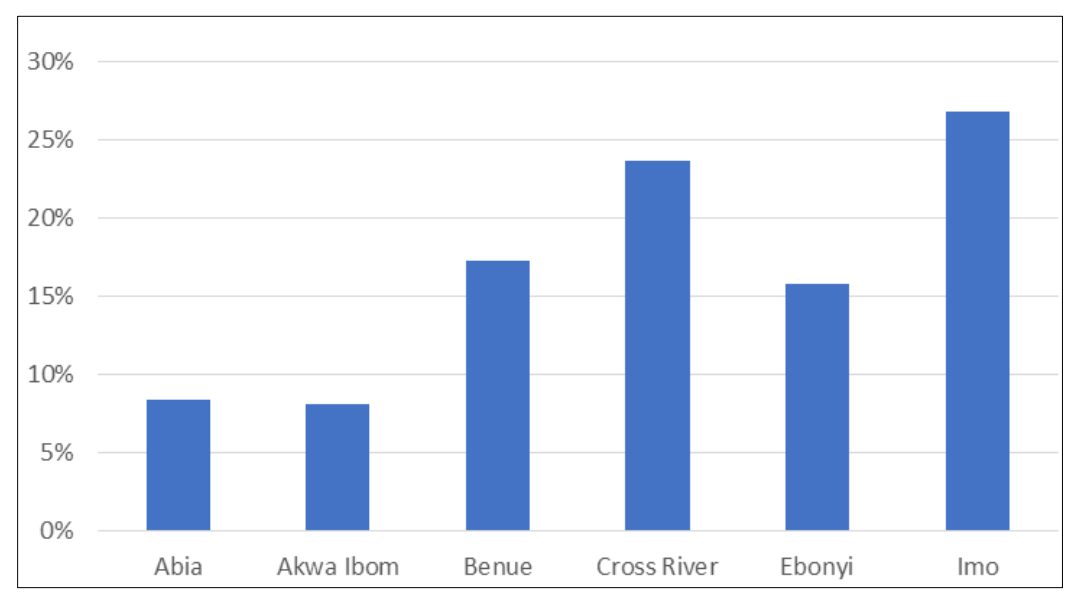

Source: National Health Logistic Management Information System (NHLMIS)

Figure 8 Proportion of new contraceptive users by states

\section{Discussion}

The stock our rates in Abia state was 0-8\%, Benue 10-30\%, Cross River 10-30\%, and Imo states 5-10\%. These are the four states implementing direct government logistics with external funding with an average stock rate of $6-20 \%$. The other state that carried out LMD through government structure and employee but without external funding was Akwa Ibom and it had a stock out rate of $20-58 \%$. This is the highest stock out rate in the geopolitical zone for the one-year period under review. Ebonyi state, the only state with a private company handling the last mile distribution had a stock out rate of $10-30 \%$ within the same period. This shows that providing funding to government owned and operated logistics system produced the lowest stock out rates of family planning commodities. However, same government owned logistics system can lead to very high stock out rates if it is starved of funds ad shown in Akwa Ibom state. Private operated logistic system for family planning commodities led to a moderately high stock out rate. When compared with the Nigerian national stock out rate, which was 20-30\%, only the government operated logistics system starved of external funding had a higher stock out rate. The three logistic models met the national benchmark stock out rate of above $10 \%$, considered as critical stock out rate, at which urgent program intervention was required.

The gaps in supply of family planning commodities among the states that operated government owned logistics system with external funding was highest in Abia state 75\%, followed by Benue state 58\%, Imo state $34 \%$ and Cross River $24 \%$. The average supply gap with this model was $48 \%$. The state-owned logistics system with no external funding seen in Akwa Ibom had a supply gap of 73\%. Private company logistics system operated in Ebonyi had the very low supply gap of $28 \%$. Once more, government owned and operated logistics system seem to perform very poorly in reducing gaps in supply of family planning commodities when starved of external funding but performed averagely when funded by external organization. The gap in supply of family planning commodities represent that fraction of the requested quantity that could not be fulfilled. Reasons from this range from inadequate quantity of commodities in the country which was worsened by the lockdown due to COVID-19 pandemic in 2019 and 2020. Other major reason was the failure to pick up and distribute all the allotted quantity by the various states.

The proportion of clients reached with family commodities who were new users through the government owned logistics system with external funding range from $8 \%$ in Abia state, $17 \%$ in Benue, $24 \%$ in Cross River to $27 \%$ in Imo state. The average proportion of FP users who were new users in this logistic model was 19\%, which was the highest of the three models. New users made up $8 \%$ of the clients reached with family planning commodities in Akwa Ibom where government logistic system without external funding was in operation. Ebonyi state with private company logistics had $16 \%$ FP clients as new users. The importance of reaching new FP users with service lies in the fact that it contributes to increasing the contraceptive prevalence rate and reducing the unmet need for family planning services. Though reaching new FP users is a function of the effectiveness of outreach and in-reach mobilization efforts, logistics of commodities also has some direct impact on the number of new FP users that can be reached at any time. This has been demonstrated in findings from several studies $[10,11]$ which support the fact that improving logistics systems performance of family planning programs improves contraceptive use. While government owned and operated logistics system with external funding seemed to reach a good proportion of new users, same system with no external funding 
produced the least proportion of new FP users. Private logistics company was associated with an average fraction of new FP users.

\section{Conclusion}

The above results show that when funded, government owned and operated logistics system can reduce stock out rate of family planning commodities and lead to reaching a very high proportion of new FP users. However, the supply gap with direct government logistic model was average at $48 \%$. The lowest supply gap of $28 \%$ was associated with the third private company logistics system.

Government owned logistics system when funded reached the highest number of new FP users among the three logistic models and therefore contributed the greatest to the reduction of unmet need in family planning and increasing the contraceptive prevalence rates in the states where this model was in use. However, when starved of fund same government logistics system was associated with the worst FP logistics outcomes such as very high stockout rates and very high supply gaps.

\section{Recommendations}

Going by the above findings and discussion the followings are recommended

- Government owned and operated logistics system needs to be strengthened with funding.

- External funding such as development partner funding should be made readily available to government owned logistics system.

- Government owned logistics are preferable in reaching new users of family planning services.

- Scale up the use of the CHANNEL e-LMIS software which improve accessibility and credibility of logistic data for decision making including forecasting, Programme implications/Lessons learnt.

- It is important to continue to strengthen capacity in logistics management through training, supportive supervision, and the availability of guidelines and/or job aids that enable health workers to do their job more accurately and effectively.

- Efforts should be made to support states to initiate and provide government led integrated public health supply chains for essential medicines that are feasible and sustainable.

- It is also critical to continue dedicated advocacy efforts to Federal and State Government to ensure budget lines for FP programming including adequate funding for distribution to the last mile and ensuring that the funds are released

- Implementation of tools for greater visibility and accountability like newly roll -out Last Mile Assurance process.

\section{Limitations}

Being a retrospective study, secondary data was used in the study. Therefore, the data used in this study was primarily collected for program management and not for scientific research. Other factors that influence logistic systems were not taken into consideration.

\section{Compliance with ethical standards}

\section{Acknowledgments}

We would like to acknowledge the following person and originations

United Nations Population Fund (UNFPA) Nigeria, Federal Ministry of Health Nigeria, State Ministries of Health in Cross River, Abia, Ebonyi, Benue, Akwa Ibom, Imo. Dr. Ummulkhulthum Bajoga Family Planning Analyst. UNFPA Nigeria Country Office

\section{Disclosure of conflict of interest}

The authors agree no conflict of interest. 


\section{Statement of informed consent}

Not relevant as there was no individual data or information.

\section{References}

[1] United Nations. Sustainable Development Goal. 3.

[2] Guttmacher Institute. Adding it up: investing in contraception and maternal and newborn health. 2017.

[3] Ali M, Cleland J, Shah IH. Causes and consequences of contraceptive discontinuation: evidence from 60 demographic and health surveys. Egypt: World Health Organization. 2012.

[4] Haider TL, Sharma M. Barriers to family planning and contraception uptake in sub-Saharan Africa: a systematic review. Int Q Community Health Educ. 2013; 33: 403-13.

[5] Campbell M, Sahin-Hodoglugil NN, Potts M. Barriers to fertility regulation: a review of the literature. Stud Fam Plann. 2006; 37: 87-98.

[6] UNFPA. The global programme to enhance reproductive health commodity security. Annual report 2013. New York: UNFPA. 2014.

[7] Nigerian National Demographic and Health Survey. 2018.

[8] National Guidelines for State-Funded Procurement of Family Planning Commodities. December 2020.

[9] Tien M, et al. "Nigeria: Reproductive health commodity security situation analysis." Arlington, VA: USAID/DELIVER PROJECT, Task Order. 2009; 1.

[10] Karim, Ali Mehryar. "The Influence of Family Planning Logistics System on Contraceptive Use." Working Paper, John Snow, Inc. /DELIVER, Arlington, Va. 2005.

[11] Karim Ali, Beize, Briton, Chimnani, Jaya, Bunde, Elizabeth. Measuring the performance of family planning supply chains in developing countries. 2007. 